\title{
Estimation of Aquifer Parameters of Limestone Aquifers - A Case Study in Thirunelvely and Kondavil of the Jaffna District
}

\author{
C. S. De Silva ${ }^{1}$ and T.Mikunthan ${ }^{2}$ \\ csdes@writeme.com
}

The productiveness of an aquifer is determined by its aquifer parameters such as specific yield and permeability. Due to the complicated features of the large diameter wells and inadequate resources to conduct pumping tests in observation bore holes, estimating aquifer parameters for better use and management of groundwater resources is extremely difficult. The conventional pumping test; distance drawdown method was not possible in the Chunnagam limestone aquifers to determine the above said parameters because there was no drawdown in observation boreholes even at $3 \mathrm{~m}$ distance. Hence, alternatively the single well test was performed in specific places; Thirunelvely and Kondavil. The water level measurements were made by a dip water meter with respect to time during the pumping and recovery phase. A semi-log plot of field drawdown data versus time is made to evaluate the transmissivity of the aquifer. The relationship between residual drawdown and time was used to find the specific yield. The radial flow numerical model previously used to estimate aquifer parameters using large diameter wells in the dry zone of Sri Lanka was used to compare the results obtained by the single well test in the study area. The hydraulic conductivity and specific yield estimated by the single well test agrees with the values obtained by the radial flow numerical model when the model results were matched with the field results. Therefore the single well test in the large diameter wells is reliable and cost effective to estimate aquifers parameters in limestone aquifers when observation bore hole data is not available. The transmissivity value of the Thirunelvely area was higher $\left(274.88 \mathrm{~m}^{2} /\right.$ day) when compared with Kondavil $\left(126.5 \mathrm{~m}^{2} /\right.$ day) and the specific yield was 0.221 and 0.201 respectively in the Thirunelvely and Kondavil areas.

\section{Introduction}

Large diameter dug wells are the main source of water supply in many areas of the world for domestic and agricultural purposes (Herbert and Kitching, 1981 \& Ruston and Holt, 1981). Groundwater from dug wells has been the source of drinking water for a vast majority of the population of Sri Lanka for thousands of years (De Silva and 
Estimation Of Aquifer Parameters Of Limestone Aquifers - A Case Study In Thirunelvely And Kondavil Of The Jaffna District

Weatherhead, 1994). The cost effectiveness and simplicity of construction and operation of these wells are often the reasons for their use. Efficient management and development of shallow groundwater resources necessitate the knowledge of aquifer parameters of the hydrologeological system (Herbert and Kitching, 1981). The occurrence of groundwater and its potential mainly depend on the characteristics and distribution of varying litho - stratigraphical units of subsurface geological formations. This is controlled to a great extent by the temporal distribution of rainfall in Sri Lanka which is distinctively bimodal in pattern. Geologically, the Jaffna Peninsula is underlain by highly fractured and karstified lime stone of the miocene age (Arumugam, 1968).

The high stress on groundwater due to the abstraction of large quantities of groundwater through pumping for irrigation and water supply, has threatened the sustainability of this natural resource. Over extraction and mismanagement adversely impacts on groundwater. Certain parts of the Jaffna Peninsula also experience salinity in groundwater as a result of over extraction (Navaratnarajah, 1994). Groundwater in such areas affects the hardcore of water supply, the quality of drinking water and agricultural production.

Groundwater availability is a prerequisite for successful cultivation where the rainfall is inadequate for cultivation. Crop losses due to water shortages have been frequently reported due to the fact that farmers do not have adequate knowledge and experience for planning their cultivation according to the availability of groundwater (Dharmasena and Karunainathan, 2004). The two properties of a water bearing medium that determine the productiveness of an aquifer are its specific yield and permeability. The specific yield relates to be the capacity of a medium to yield water for a given change in a water table or the piezometric need and the permeability relates to its capacity to transmit water. A typical shallow well can irrigate $0.2-0.8$ ha depending upon the spread, specific yield and the permeability of the aquifer (Dharmasena and Karunainathan, 2004). Hence estimation of aquifer parameters is vital for the assessment of groundwater potential.

\section{Statement of problem}

Due to very significant well storage in large diameter wells, conventional methods of pumping test analysis based on Thesis (1938) 
equation are unsuitable as it is for small diameter wells where the well storage is negligible. The pumping test analysis is essential to estimate the aquifer parameters for groundwater resources assessment. The results revealed that there was no drawdown even in the observation borehole drilled at $3 \mathrm{~m}$ distances from the pumping well at Chunnakam in the limestone aquifer zone with $100 \mathrm{~L} / \mathrm{s}$ (Feasibility report, 2006). Therefore, there was no possibility of analyzing pumping tests through the distance draw down method. Further, most of the analytical methods used are for small diameter wells where well storage is negligible. Constructing small diameter observation boreholes for conducting the pumping test will be very expensive and farmers too are not willing to pump the well water till the constant rate is achieved due to limited groundwater resources. Therefore it is essential to identify a cost effective method to estimate the aquifer parameters with available data from large diameter wells.

Objective of the study: To estimate the specific yield and transmissivity of limestone aquifers using large diameter well pumping test data.

\section{Material and Methods}

Both analytical and numerical methods can be used to study the aquifer parameters using large diameter wells. Using certain analytical techniques it is possible to include the features of large diameter wells such as the effect of seepage face. Seepage face occurs between the aquifer water table and the well water level. Numerical methods are also appropriate when interpreting field results for large diameter wells. They also represent the well storage and decreasing pumping rates with increasing drawdown which occur with farmers' pumps. Therefore in this study the pumping test is analyzed by two analytical methods and one numerical method to compare and validate the results.

\section{Pumping test}

Twenty wells were selected from the Chunnakam aquifer zone at specific places in Thirunelvely, and Kondavil for the pumping tests. All the selected wells were open hand dug shallow wells. The depth varied from $2 \mathrm{~m}$ to $10.5 \mathrm{~m}$ and the diameter varied from $2.8 \mathrm{~m}$ to $3.2 \mathrm{~m}$. Pumping tests were done in the driest period (July and August) in 2009 and during the normal pumping hours for irrigation purposes by farmers. Pumping tests were carried out at or near the proposed rate of water abstraction. Influences such as from the pumping of neighboring wells shortly before or during the test and for a period of recovery 
Estimation Of Aquifer Parameters Of Limestone Aquifers - A Case Study In Thirunelvely And Kondavil Of The Jaffna District

afterward were avoided. The neighboring wells were monitored during the tests. The topography is even and there were no special boundaries like surface water bodies to influence the observations.

The initial water level in the pumping test well was measured. The rate of pumping was measured and monitored continuously. Groundwater levels were measured by a battery powered groundwater probe. Water levels during recovery were monitored until the water levels recovered to the pre-test level.

\section{Analytical methods}

In the analytical methods, data from the pumping phase or recovery phase or both the pumping and the recovery phases, are available to interpret the well parameters. In this study, pumping phase data was used to calculate transmissivity by using the Cooper- Jacob single well model (De Smedt, 2005) and data from the recovery phase was used to calculate the specific yield of the aquifer by the Slicnter recuperation method (Arumugam, 1968; Ragunath, 1987 and Santhosh Kumar, 1994).

Cooper- Jacob single well model (De Smedt, 2005)

The analysis of the drawdown in a small diameter pumping well had been done with the Jacob time drawdown method by using a semilogarithmic graph. In this method a semi-log plot of the field drawdown data (linear scale) versus time (natural log scale) is made. A straight line is then drawn through the field data points. The value of the drawdown per log cycle of time, $\Delta \mathrm{s}$ is obtained from the slope of the graph. Then transmissivity is determined from the slope of the straight line (De Smedt, 2005).

In which

$$
T=\frac{2.3 Q}{4 \pi \Delta\left(h_{o}-h\right)}
$$

$\mathrm{T}=$ Transmissivity $\left(\mathrm{m}^{2} /\right.$ day $)$

$\mathrm{Q}=$ Flow rate $\left(\mathrm{m}^{3} /\right.$ day $)$

$(h o-h)=$ Drawdown, per one log cycle 
Slicnter Recuperation Method (Ragunathan, 1987 and Santoskumar, 1994)

The specific yield of the aquifer was calculated with the depth of recuperation in a known time as follows. If the water level inside the well rises from $s_{1}$ to $s_{2}$ in time $t$ and if $s$ is the drawdown at any time $t$, from Darcy's law,

$$
Q=K A I=K A s / L=C A s
$$

Figure 1: Typical diagram of pumping well

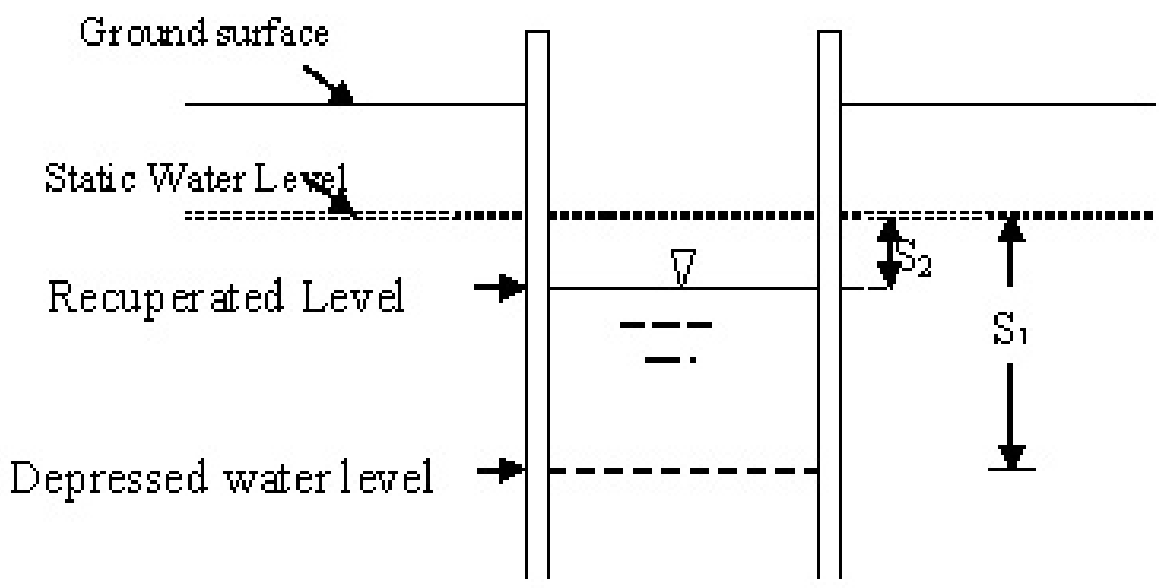

Where ' $\mathrm{s}$ ' is the head loss in a length of flow path $\mathrm{L}$ and $\mathrm{C}$ is a constant $=\mathrm{K} / \mathrm{L}$ which can be determined after integrating

$$
Q d t=A d s
$$

Negative sign indicate a decrease in drawdown or depression head.

Which gives

$$
\begin{gathered}
C A s d t=-A d s \\
C \int_{0}^{t} d t=\int_{s 1}^{s 2}-\frac{d s}{s} \\
C=\frac{2.303 * \log s 1 / s 2}{t}
\end{gathered}
$$


Estimation Of Aquifer Parameters Of Limestone Aquifers - A Case Study In Thirunelvely And Kondavil Of The Jaffna District

C-specific yield of the well per unit cross sectional area per unit depression head.

\section{Radial Flow Numerical Model}

Due to the complexity of the interaction between large diameter wells and the aquifers, numerical/mathematical methods can often provide a more realistic representation. In radial flow numerical models, finite difference solutions to the differential equations are obtained instead of analytical solutions as in the example given by Papadopulos and Cooper (1967). Both the radial and time co-ordinates are divided into discrete intervals which increase logarithmically. Using these numerical methods it is possible to include all of the features in a single numerical solution. This model is based on a finite difference approximation in time and space and can be run on micro computers. The essential feature of any reliable method is that the number of simplifying assumptions is minimal.

The following features are common to most pumping tests in large diameter wells.

- Tests consist of a pumping phase of 1 to 4 hours and a recovery phase of 20 to 23 hours.

- Unless great care is taken the pump discharge will decrease as the drawdown in the pumped well increases.

- Using suitable devices, in which a reducing proportion of the water is returned to the well, it is possible to achieve a constant discharge.

- Water is drawn from the aquifer during the pumping and recovery phases.

- The water table in the well and the phreatic surface of the aquifer are at different elevations due to the seepage face.

- The well may be partially penetrating.

- Vertical flow components occur in the vicinity of the well. 
- The saturated thickness of the aquifer usually decreases during the test.

- The aquifer may exhibit layering with the hydraulic conductivity varying with depth.

- Interference from neighboring wells or the influence of neighboring zones of lower hydraulic conductivity may modify the response to pumping.

This is a formidable list of features, yet any one may have a dominant effect on the response of the aquifer to pumping. Therefore, if a method of analysis is unable to represent (at least approximate) each of these features, it may lead to erroneous results.

Radial flow numerical models can be used to analyze a wide variety of pumping tests in large diameter wells. In order to estimate the aquifer parameters in large diameter wells, the radial flow numerical model of Rathod and Rushton (1984) was used successfully with modifications to analyze the pumping test in large diameter wells with data in both the pumped well and observation boreholes in Sri Lanka (De Silva and Rushton, 1996). The reason for selecting this radial flow model to use in the study site was that this model has been widely used in India and other hard rock aquifer countries, where the aquifer conditions and farming practices were more or less similar to the study site conditions and a satisfactory representation of the real field conditions were obtained (Rushton and Holt, 1981).

This model includes modifications for features such as well storage, seepage face, effective outer boundary and variable saturated depth. Well storage was simulated by having a very high value of transmissivity to simulate the horizontal water level in the well. The large radius of the well with the appropriate well storage was directly included in the standard numerical model together with variations in the saturated depth. A seepage face is always present on the well face between the well water level and the phreatic surface of the aquifer and occurs because of vertical flow components in the vicinity of the well. In the numerical model the seepage face is represented as an additional drawdown which is proportional to the quantity of water flowing from the aquifer into the well. The technique used to include this additional drawdown is to decrease the effective horizontal hydraulic conductivity for the mesh interval adjacent to the well face. Therefore the same model of De Silva and Rushton (1996) is used for 
Estimation Of Aquifer Parameters Of Limestone Aquifers - A Case Study In Thirunelvely And Kondavil Of The Jaffna District

data of a pumped well only in a limestone aquifer to validate the results obtained by the analytical methods.

\section{Results and Discussion}

\section{Aquifer Response}

Drawdown is the difference between the water level at any time during the test and the position of water level prior to pumping. Drawdown is very rapid at first. As pumping continues and the cone of depression expands, the rate of drawdown decreases. The recovery of the water level under ideal conditions is a mirror image of the drawdown. The pumping test was continued long enough to get sufficient drawdown of the aquifer to the bottom of the foot valve. The pumping phase ranged from 15 to 240 min depending on the method of withdrawals.

Depending on whether a kerosene oil water pump or an electrical motor water pump was used discharge varied from $120-2951 / \mathrm{min}$. Discharge was kept constant throughout the test. The drawdown ranged from $40 \mathrm{~cm}$ to $120 \mathrm{~cm}$. The maximum time of the recovery phase was $540 \mathrm{~min}$.

The aquifer response during the two pumping tests is depicted in Figure 2 . In some wells, the pumping phase was very short (15 min ) and the recovery lasted for $500 \mathrm{~min}$ (Kondavil). The pumping phase varied from 70-200 min and 20-48 min respectively at the Thirunelvely (Figure 2a) and at the Kondavil (Figure 2b) wells. The recovery phase varied from 80-540 $\mathrm{min}$, and 95-600 min respectively at the Thirunelvely, and at the Kondavil wells. In the Thirunelveli the limestone aquifer, most of the wells show a 100\% recovery 2 hours after the pump was switched off. Only one well shows a 100\% recovery after $1 \frac{1}{2}$ hours. Most of the wells in Kondavil show a 100\% recovery 6 hour after the pump was switched off. 
Figure 2: $\quad$ Response of aquifer during pumping and recovery phase in (a) Thirunelvely (b) Kondavil.

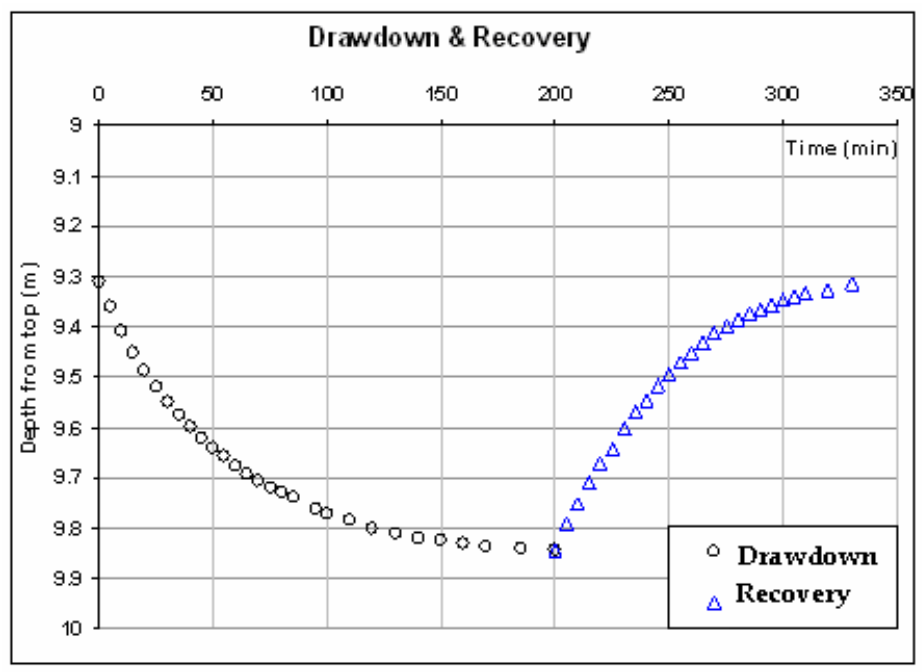

(a)

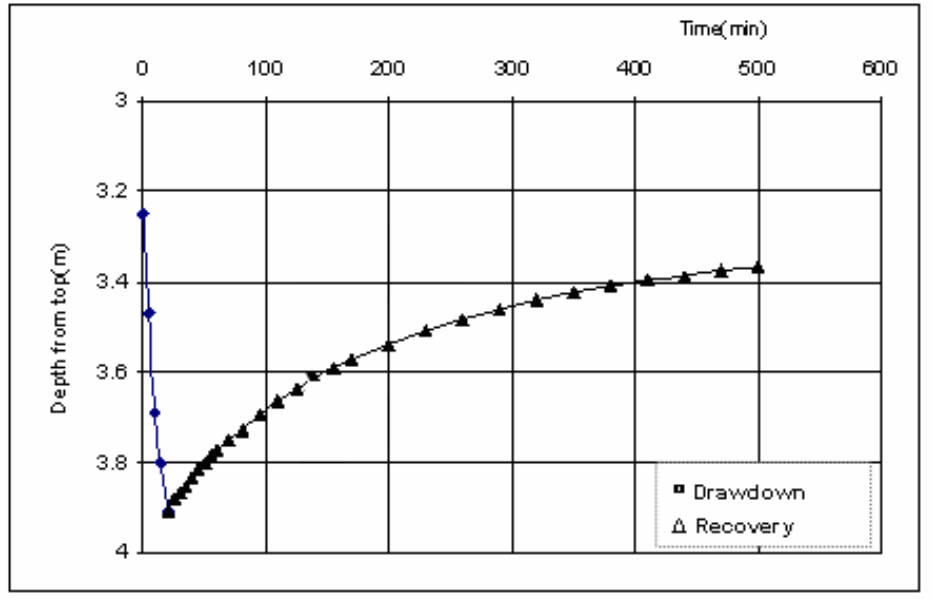

(b) 
Estimation Of Aquifer Parameters Of Limestone Aquifers - A Case Study In Thirunelvely And Kondavil Of The Jaffna District

\section{Analytical methods}

\section{Estimation of Transmissivity}

Transmissivity is dependent on fissures, fractures and weathering of aquifers. Sirimanne and Vaidya (1955) stated that there is always a possibility of large variations within an aquifer because openings in the limestone may range from microscopic original pores to large solution caverns which form subterranean channels which are sufficiently large to carry the entire flow. Figure 3 shows time drawdown analysis done by the Cooper and Jacob method of one of the wells in Thirunelvelly. Transsmissivity values estimated by the Cooper and Jacob method in the Thirunelvely limestone aquifer range from $166-293 \mathrm{~m}^{2} /$ day with the average value of $274.88 \mathrm{~m}^{2} /$ day.

These values range from $86-144 \mathrm{~m}^{2}$ /day in the Kondavil area with the average value of $126.5 \mathrm{~m}^{2} /$ day. Out of the twenty wells tested, transmissivity could not be estimated for seven wells (two from Thirunelvely and five from Kondavil) due to the short duration of pumping. The available aquifer parameters for other areas in the Jaffna Peninsula were estimated through the distance drawdown method used by other researchers (Feasibility study, 2006) are listed in table 1.

Table 1: $\quad$ Available estimated transmissivity values

\begin{tabular}{llll}
\hline Aquifer type & $\begin{array}{l}\text { Transmissivity } \\
\left(\mathrm{m}^{2} / \text { day }\right)\end{array}$ & $\begin{array}{l}\text { Hydraulic } \\
\text { conductivity } \\
(\mathrm{m} / \text { day })\end{array}$ & $\begin{array}{l}\text { Storage } \\
\text { coefficient }\end{array}$ \\
\hline Chundikulum & 420 & 35 & 0.27 \\
Palai & $2-8$ & $0.2-1.8$ & - \\
Vadamarachchi & 420 & 35 & 0.27 \\
Manatkadu & $315-525$ & $26-43$ & $0.18-0.32$ \\
Kayts & $28-35$ & $7-10$ & - \\
Chunnagam & - & 13.3 & - \\
\hline
\end{tabular}




\section{Estimation of specific yield}

The water yielding capacity of an aquifer can be expressed in terms of its storage coefficient or specific yield. A storage coefficient is the volume of water that an aquifer releases from or takes into storage per unit surface area of the aquifer per unit change in the head to the aquifer. Figure 4 shows the result of the recovery of pumping in large diameter wells in Thirunelvelly and Kondavil. The specific yield of the limestone aquifer varies from 0.15 to 0.29 with the average of 0.228 at Thirunelvelly. It was 0.11 to 0.24 at Kondavil with the average of 0.204. This specific yield value is very close to the value $(0.23)$ used for groundwater studies in Chunnakam limestone aquifer (Feasibility report, 2006).

Figure 3: $\quad$ Cooper - Jacob time drawdown analysis

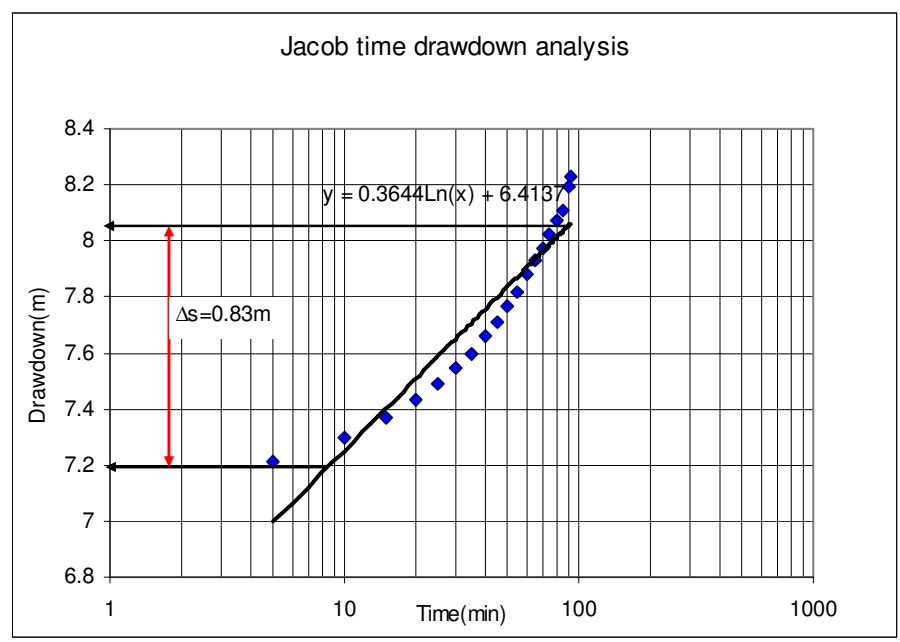

\section{Radial flow numerical model}

Pumping tests were analysed using the radial flow model (De Silva and Rushton, 1996). The model results were compared with the drawdown in the pumped well. Inputs to this model were well diameter, well depth or saturated depth, pumping rate of the particular pumping test and rest water level. Several pumping tests were compared with modeled and observed water levels during the pumping and the recovery phases. One pumping test from a large diameter well in 
Estimation Of Aquifer Parameters Of Limestone Aquifers - A Case Study In Thirunelvely And Kondavil Of The Jaffna District

Thirunelvelly is shown in Figure 5 as an example.

Figure 4: $\quad$ Relationship between times to recovery in (a) Thirunelvelly and (b) Kondavil.

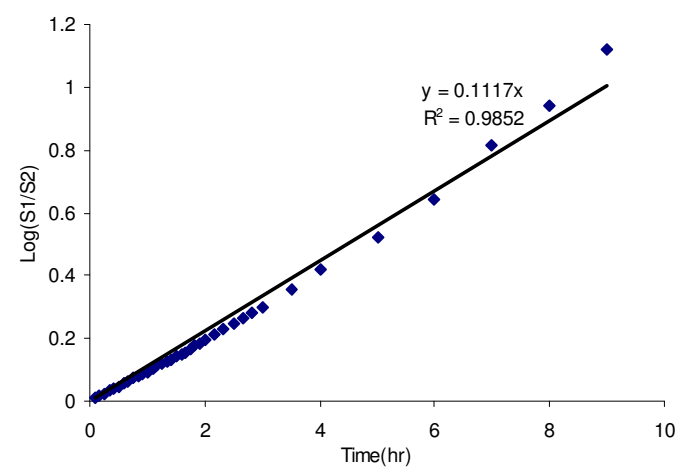

(a)- Thirunelvely

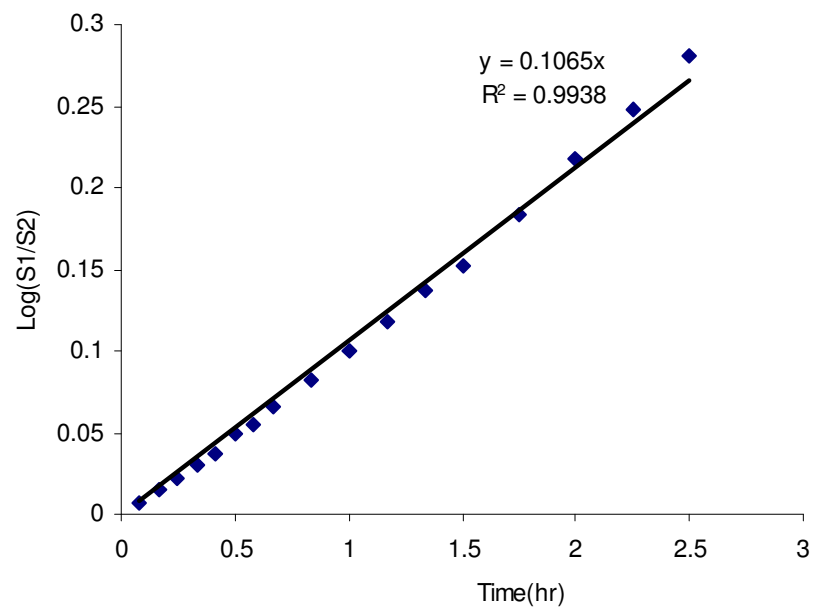

(b)-Kondavil 
Data used for input parameters were as follows:

$\begin{array}{lll}\text { Well diameter } & = & 3.2 \mathrm{~m} \\ \text { Saturated Depth } & = & 10.2 \mathrm{~m} \\ \text { Pumping rate } & = & 308 \mathrm{~m}^{3} / \mathrm{d} \\ \text { Pumping duration } & = & 200 \mathrm{~min} \\ \text { Rest Water Level } & = & 9.31 \mathrm{~m}\end{array}$

The initial values of hydraulic conductivity and the specific yield were obtained by using the type curve of Papadopulos and Cooper (1967) for the pumping phase. Modifications were then made to the hydraulic conductivity, specific yield and well loss factor until adequate agreements were obtained between the field and modeled drawdown results for both pumping and recovery phases. The estimated parameter values for Thirunelvelly were as follows:

Horizontal hydraulic conductivity $=32 \mathrm{~m} /$ day

Specific yield

Well loss factor

$$
=0.21
$$

$$
=8
$$

In general the agreement with the field results was satisfactory. Therefore it shows that the single well pumping test in a large diameter well could be used successfully to estimate the aquifer parameters as it has close agreement with the results of the radial flow numerical model. 
Figure 5. Comparison of best fit between simulated numerical results and field observed results in Thirunelvely (Well no 8).

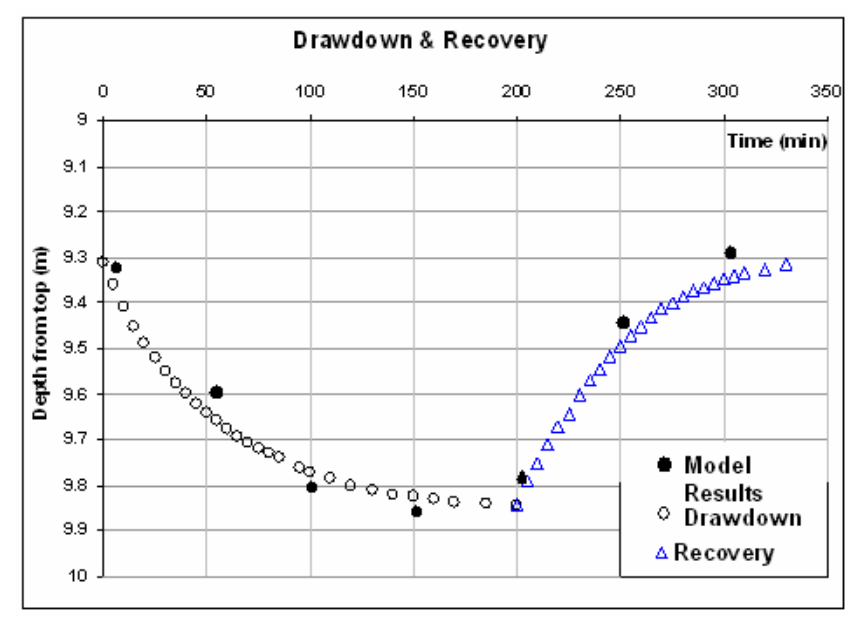

The limitations of this study are that an exact fit was most unlikely since this would require that the cross sectional area of the well remained precisely constant and that the well water level was measured to the nearest millimeter. The differences between the field and modeled values were consistent with the tolerances of the field measurements and the idealizations introduced in the numerical model. But the sensitivity analysis was not conducted as there were no observation bore holes installed in the study area because there were no changes in the water level even in close proximity to the pumped well.

\section{Conclusion}

The aquifer parameters; specific yield and transmissivity could be determined from single well pumping tests in large diameter dug wells in the limestone aquifer. The specific yield of the limestone aquifer varies from 0.15 to 0.29 with the average value of 0.228 at Thirunelvely and 0.11 to 0.24 at Kondavil with the average value of 0.204 .

Transsmissivity values in the Thirunelvely limestone aquifer ranges from $166-293 \mathrm{~m}^{2} /$ day with the average value of $274.88 \mathrm{~m}^{2} /$ day and in Kondavil area values ranges from $86-144 \mathrm{~m}^{2} /$ day with the average value of $126.5 \mathrm{~m}^{2} /$ day 
C. S. De Silva and T. Mikunthan

\section{References}

Arumugam, S. (1968). Development of ground water and its exploitation in the Jaffna peninsula. Transactions of the Institution of Engineers, Ceylon. 1: 17-26.

De Silva, C.S. and Weatherhead, K. (1994). The use of large diameter wells for supplementary irrigation in the Dry Zone of Sri Lanka. Water Down. Adelaide, Australia, 21 - 25 November, 1998.

De Silva, C.S. and Rushton, K.R. (1996) Interpretation of the behaviour of agrowell systems in Sri Lanka using radial flow models. Journal of Hydrological Sciences 41(6) 825-835.

De Smedt, F. (2005). Basic groundwater hydrology, Department of Hydrology and Hydraulic Engineering, Faculty of Applied Sciences, Free University, Brussels, Pleiniaan.

Dharmasena, P.B. and T. Karunainathan (2004). Characteristics of regolith aquifers and their save exploitation through agro-wells. Annals of the Sri Lanka Department of Agriculture. 6: $79-87$.

Feasibility report. 2006. A feasibility study for a water supply and sanitation system for the Jaffna Peninsula. ADB project. Project No: 5068020. National Water Supply and Drainage Board. Jaffna, Sri Lanka.

Herbert, R. and R. Kitching. (1981). Determination of aquifer parameters from large diameter dug well pumping tests. Groundwater. 19(6): 593-599.

Navaratnarajah, V. (1994). Water problems in the Jaffna peninsula, 20 th WEDC Conference in Affordable Water Supply and Sanitation. pp 160170 .

Papadopulos, I.S. and Cooper, H.H. (1967). Drawdown in a well of large diameter. Water Resources Research 3, 241-244

Ragunathan, H. M. 1987. Groundwater. Willy Eastern Limited, New Delhi, India. pp $240-242$.

Rathod, K.S. and Rushton, K.R. (1989) Numerical analysis of pumping test analysis using micro computers. Groundwater, 22(5), 602-608. 
Estimation Of Aquifer Parameters Of Limestone Aquifers - A Case Study In Thirunelvely And Kondavil Of The Jaffna District

Rushton, K. R. and S. M. Holt. (1981). Estimating aquifer parameter for large diameter wells. Groundwater. 19(5): 505-509.

Santhosh Kumar, G. (1994). Water Supply Engineering. Khanna Publishers, Delhi, India. pp143 -171.

Thesis, C. V. (1935). The relation between the lowering of the rate and duration of discharge of a well using ground water storage. Reports and papers, Hydrology, U.S. Geographical Survey, Washington, D.C. 